\title{
SUPERAÇÃO DA DORMÊNCIA EM SEMENTES DE MUTAMBA (Guazuma ulmifolia Lam. - STERCULIACEAE) ${ }^{1}$
}

\author{
Severino de Paiva Sobrinho ${ }^{2}$, Aline Gonçalves Siqueira ${ }^{3}$, Petrina de Bessa Morais ${ }^{4}$ e Sérgio José da \\ Silva ${ }^{5}$
}

\begin{abstract}
RESUMO - A Guazuma ulmifolia Lam. possui sementes com acentuada impermeabilidade a água, o que dificulta sua germinação. Avaliou-se o efeito do período de imersão das sementes em ácido sulfúrico $(0,4,8,12 \mathrm{e}$ 16 min) e em água a $60^{\circ} \mathrm{C}$ por $0,4,8,12$ e $16 \mathrm{~min}$, na emergência de plântulas, início da emergência e índice de velocidade de emergência. O experimento foi realizado em Laboratório de Biologia, em delineamento inteiramente casualizado em fatorial 2 (tratamento pré-germinativo) x 5 (períodos de imersão), com três repetições de 20 sementes. O precondicionamento das sementes em ácido sulfúrico como em água mostrou-se eficiente na superação da dormência dessa espécie, promovendo aumento na porcentagem de emergência de plântulas e velocidade de emergência e redução no tempo para o início da germinação. A eficiência do tratamento químico com ácido sulfúrico foi obtida com um tempo de imersão de 8 min, enquanto no tratamento físico com água a $60^{\circ} \mathrm{C}$ a eficiência foi obtida com o tempo de imersão de $16 \mathrm{~min}$.
\end{abstract}

Palavras-chave: Escarificação, Dormência e Germinação.

\section{OVERCOMING SEED DORMANCY IN MUTAMBA (Guazuma ulmifolia Lam. - STERCULIACEAE)}

\begin{abstract}
Guazuma ulmifolia Lam. have seed with high water impermeability which impairs germination. The effect of the immersion time (0, 4, 8, 12 and 16 minutes) of Guazuma ulmifolia Lam. in concentrated sulfuric acid, and water at $60^{\circ} \mathrm{C}$ for $0,4,8,12$ and 16 minutes were evaluated for emergency and vigor (start of the emergency and speed index). The experiment was carried out in the Biology Laboratory, in a completely randomized design in $2 \times 5$ factorial (2 pre-emergency treatment and 5 immersion times), with three replicates of the 20 seeds. The pre-conditioning of seeds in sulphuric acid as well as in water at $60^{\circ} \mathrm{C}$ was efficient in breaking the seed dormancy and also for increasing the emergence percentage and speed, and reduction of the time for onset of emergence. The efficiency of this chemical treatment with sulphuric acid was obtained with a immersion time of 8 minutes, while in the physical treatment with water at $60^{\circ} \mathrm{C}$, the efficiency was obtained with immersion time of 16 minutes.
\end{abstract}

Keywords: Dormancy, Germination and Scarification.

\section{INTRODUÇÃOO}

A mutamba (Guazuma ulmifolia Lam.) é uma espécie comum no Cerrado brasileiro, pertence à família Sterculiaceae, sendo popularmente conhecida como mutambo, mutamba, fruta-de-macaco, embira, embireira e mutamba verdadeira, apresentando altura entre $8 \mathrm{~m}$ e $16 \mathrm{~m}$ e tronco entre $30 \mathrm{~cm}$ e $50 \mathrm{~cm}$ de diâmetro (LORENZI, 2002). Ainda segundo esse autor, esta espécie tem ocorrência em quase todo o país, desde a Amazônia até o Paraná, principalmente nas Florestas Latifoliadas Semidecíduas e, segundo Barbosa e Macêdo (1993), em toda a América Latina.

\footnotetext{
${ }^{1}$ Recebido em 04.05.2007 aceito para publicação em 04.06.2012.

${ }^{2}$ Universidade do Estado de Mato Grosso, Departamento de Agronomia. E-mail: <paivasevero@ unemat.br>.

${ }^{3}$ Programa de Pós-Graduação em Ciências de Materiais . Universidade de Brasília, UNB, Brasil. E-mail:<alineueg@ hotmail.com>.

${ }^{4}$ Graduação em Biologia. Universidade Estadual de Goiás, UEG, Brasil. E-mail: <petbessa@ hotmail.com>.

${ }^{5}$ Universidade Estadual de Goiás, Unidade Universitária de Porangatu. E-mail: <sergiosilva@ueg.br>.
} 
No Brasil, a estação de florescimento vai do final de setembro até o início de novembro, e os frutos dessa floração amadurecem nos próximos meses de agosto e setembro (ARAÚJO NETO; AGUIAR, 1999).

Para a produção de mudas de mutamba é necessário superar a dormência natural das sementes, causada pela impermeabilidade do tegumento à água, a qual é denominada semente dura. Na maioria das espécies silvestres, pouco se conhece acerca das condições para germinação (HEYWOOD, 1989).

A importância ecológica da dormência é devida, principalmente, ao bloqueio que impõe à germinação, quando as condições ambientais lhe são favoráveis, porém as perspectivas de futuro estabelecimento e crescimento das plântulas não são promissoras, sendo também importante para a distribuição da germinação de um lote de sementes no tempo e no espaço (EIRA; CALDAS, 2000).

Carvalho e Nakagawa (2000) afirmaram que as sementes da maioria das espécies germinam prontamente quando lhe são dadas condições ambientais favoráveis. Porém, para Kramer e Kozlowsk (1972) as sementes de cerca de dois terços das espécies arbóreas apresentam certo grau de dormência, que pode ser superada com a utilização de tratamentos pré-germinativos.

Quando as sementes apresentam dormência, o estudo de sua viabilidade pode ser comprometido devido ao baixo índice de germinação. Dessa forma, é necessário e importante o emprego de metodologias que visem superar a dormência. Esta constitui uma característica importante em lotes de sementes das espécies cultivadas, sendo, todavia, um dos problemas mais sérios na conservação de germoplasma de espécies silvestres, já que estas produzem frequentemente sementes dormentes (SMIDERLE; SOUZA, 2003).

A dormência do tipo tegumento impermeável à água pode ser superada através da escarificação, ou seja, qualquer tratamento que promova a ruptura ou enfraquecimento do tegumento, permitindo a penetração da água e dando início ao processo de germinação (MAYER; POLJAKOFF-MAYBER, 1989).

Quando a semente cai no solo, a escarificação pode ocorrer devido ao aquecimento do solo seco ou úmido por temperaturas alternadas, permitindo, dessa forma, a entrada de água para o interior da semente. Esse processo pode ocorrer, também, pela ação de ácidos quando da ingestão das sementes por animais dispersores, além da ação dos microrganismos do solo (VAZQUEZYANES; OROZCO-SEGOVIA, 1993).

Segundo Eira et al. (1993), todos esses tratamentos apresentam vantagens e desvantagens, de forma que cada um deles deve ser estudado, levando-se em conta, também, o custo efetivo e sua facilidade de execução. Deve-se, também, tomar os devidos cuidados, para que na aplicação de determinado tratamento de superação de dormência em um lote de sementes não prejudique aquelas que possuem dormência menos acentuada.

A eficiência do ácido sulfúrico foi comprovada na superação de dormência de sementes de Senna macrotheri (Colldadon) Irwin e Barneby (SANTARÉM; AQUILA, 1995; LEMOS-FILHO et al., 1997), Cassia excelsa Schrad (JÉLLER; PEREZ, 1999), Bowdichia virgilioides Kunth (SMIDERLE; SOUZA, 2003), Enterolobium contortisiliqunn Vell. (SCALON et al., 2006a) e Zizyphus joazeiro Mart. (ALVES et al., 2006) e uso de água com temperatura elevada na superação da dormência em sementes de Leucaena leucocephala Lam. (TELES et al., 2000), Trifolium riograndense Burkart e Desmanthus depressus Humb (SUÑÉ; FRANKE, 2006) e Jacarandá cuspidifolia Mart. (SCALON et al., 2006b).

Segundo Araújo Neto (1997), as sementes de mutamba apresentam altas taxas germinativas quando imersas em ácido sulfúrico, com maior percentual de germinação $(54,54 \%)$ para período de imersão igual a 70 min. Já Nunes et al. (2006) observaram que a escarificação com ácido sulfúrico concentrado por 5 min não foi capaz de superar a dormência, porém observaram que a utilização de água quente a $70{ }^{\circ} \mathrm{C}$ foi suficiente para quebrar a dormência $(66,8 \%$ de germinação). Araújo Neto e Aguiar (2000) verificaram que o melhor tempo de imersão das sementes de mutamba em ácido sulfúrico concentrado é de 50 min (62,1\% de germinação)

Desse modo, este trabalho teve como objetivo avaliar o efeito de tratamentos físico e químico na superação da dormência de sementes de mutamba.

\section{MATERIAL E MÉTODOS}

O trabalho foi realizado no Laboratório de Biologia da Universidade Estadual de Goiás, em Porangatu, GO, a $13^{\circ} 26^{\prime} 27^{\prime \prime}$ de latitude sul e $49^{\circ} 08^{\prime}$ '56" de longitude 
oeste de Greenwich. A cidade encontra-se numa altitude média de $390 \mathrm{~m}$, com temperatura média de $30^{\circ}$ e clima tropical semiúmido.

Os frutos de mutamba foram colhidos no Município de Porangatu, GO, e levados para o Laboratório de Biologia da Universidade Estadual de Goiás, onde foram abertos para remoção das sementes com cuidado para não danificá-las. Após a remoção, as sementes foram submetidas aos procedimentos de escarificação: imersão em água quente (escarificação térmica) a $60^{\circ} \mathrm{C}$ por 4, 8, 12 e 16 min e imersão em ácido sulfúrico (escarificação química) concentrado por 4, 8, 12 e 16 min; e as sementes da testemunha constituíram o tempo zero de imersão. As sementes tratadas com ácido sulfúrico foram lavadas em água corrente, para remover todo o excesso de ácido.

Depois de submetidas aos tratamentos, as sementes foram semeadas em bandejas plásticas de fundo perfurado, entre areia lavada previamente peneirada e esterilizada e umedecida com quantidade de água equivalente a $60 \%$ de sua capacidade de retenção. Foram avaliadas as seguintes características: Emergência - utilizaram-se 60 sementes por tratamento, em três repetições. As contagens do número de sementes emergidas iniciaram-se aos seis dias e estenderam-se até os 24 dias após a semeadura, à exceção da testemunha. O critério utilizado foi o de plântulas normais que apresentavam as estruturas essenciais perfeitas (BRASIL, 1992), sendo os valores expressos em percentagem; Início da emergência - corresponde ao número de dias após o semeio, em que cada tratamento apresenta sua primeira semente emergida; e Índice de velocidade de emergência (IVE) - foram feitas contagens a cada dois dias, durante 18 dias, das plântulas normais, sendo o índice calculado conforme Manguire (1962).

O experimento foi realizado em delineamento inteiramente casualizado em fatorial 2 (tratamento prégerminativo) x 5 (períodos de imersão), com três repetições de 20 sementes. Os dados foram submetidos a análises de variância e de regressão polinomial.

\section{RESULTADOS E DISCUSSÃO}

Os dados de emergência de plântulas encontram-se na Figura 1. A regressão polinomial dos períodos de exposição ao ácido sulfúrico concentrado apontou um modelo quadrático, ou seja, a percentagem de emergência de plântulas cresceu à medida que aumentou o tempo de imersão da semente no ácido sulfúrico concentrado, atingindo o máximo de $34 \%$ em $8 \mathrm{~min}$. Esses resultados concordam com os de alguns autores, como Smiderle e Sousa (2003), com sementes de paricarana (Bowdichia virgilioides Kunth), quando utilizaram ácido sulfúrico por 5 min; Teles et al. (2000), com sementes de leucena (Leucaena leucocephala Lam.), também utilizando ácido por igual período; Barbosa et al. (2005), com sementes de Strilitza regiane, obtiveram máxima germinação quando imersas em ácido sulfúrico por $7 \mathrm{~min}$; e Scalon et al. (2006a) consideraram que o tratamento mais adequado para a germinação de sementes de orelhade-macaco (Enterelobium contortisiliqunn (Vell.) Morang) é a escarificação com ácido sulfúrico por 5 min. Para sementes de juazeiro (Zizyphus joazeiro Mart.), Alves et al. (2006) verificaram que a escarificação com ácido sulfúrico mostrou-se bastante benéfica. Entretanto, esse percentual de emergência foi inferior ao obtido por Araújo Neto (1997), que foi de 54,54\%, e também inferior ao obtido por Araujo Neto e Aguiar (2000), que foi de $62,1 \%$.

As sementes de mutamba imersas em água a $60^{\circ} \mathrm{C}$ apresentaram aumento no percentual de plântulas emergidas em relação à testemunha (Figura 1). O aumento no tempo de imersão elevou o percentual de plântulas emergidas, sendo a maior emergência (77\%) obtida no

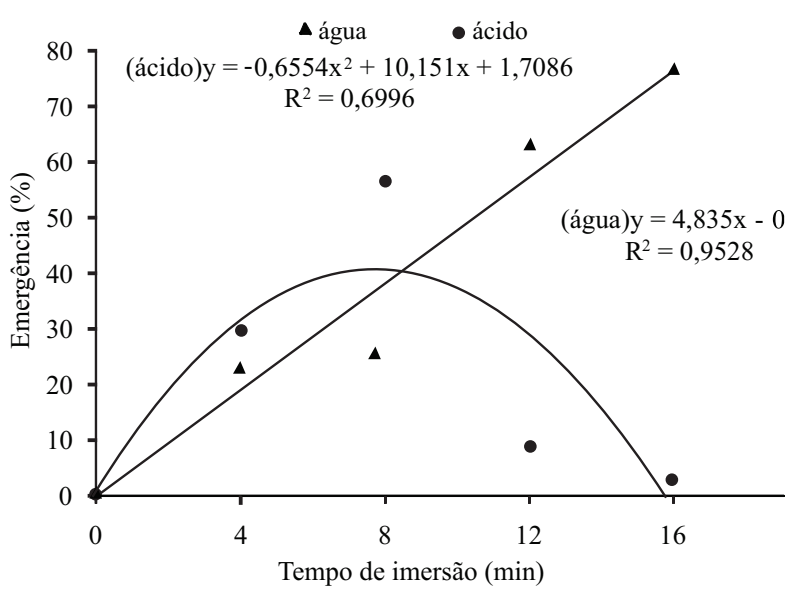

Figura 1 - Emergência de plântulas de mutamba (Guazuma ulmifolia Lam.) após a imersão em água $(\boldsymbol{\Delta}) \mathrm{e}$ imersão em ácido sulfúrico $(\bullet)$ por diferentes períodos.

Figure 1 - Emergency of Guazuma ulmifolia Lam. seedlings, after immersion in water $(\mathbf{\Delta})$ and immersion in sulfuric acid (•) for different times.

Revista Árvore, Viçosa-MG, v.36, n.5, p.797-802, 2012

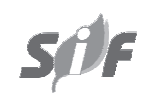


período de 16 min. Esse resultado sugere que essas sementes podem ser submetidas a um período maior que 16 min de imersão em água a $60^{\circ} \mathrm{C}$. Entretanto, Nunes et al. (2006), trabalhando com escarificação térmica a $70{ }^{\circ} \mathrm{C}$, obtiveram percentual de emergência menor $(66,8 \%)$.

Os valores referentes ao início da emergência das sementes de mutamba imersas em ácido sulfúrico e em água a $60{ }^{\circ} \mathrm{C}$ encontram-se na Figura 2. Os valores tanto das sementes imersas em ácido sulfúrico quanto aquelas imersas em água a $60^{\circ} \mathrm{C}$ não se ajustaram a nenhum modelo de regressão. $\mathrm{O}$ início da emergência da testemunha ocorreu aos 60 dias após o semeio; nos demais tratamentos, o início da emergência ocorreu entre o sexto e o sétimo dia depois do semeio. O tempo para o início da emergência foi cerca de 10 vezes menor do que o da testemunha. Dessa forma, verificou-se que os tratamentos foram eficientes e permitiram um ganho de tempo na produção de mudas de mutamba e maior uniformidade na idade das mudas.

O índice de velocidade de emergência dos tratamentos com ácido sulfúrico ajustou-se ao modelo quadrático, enquanto os tratamentos com água a 60 ${ }^{\circ} \mathrm{C}$ se ajustaram ao modelo linear (Figura 3).

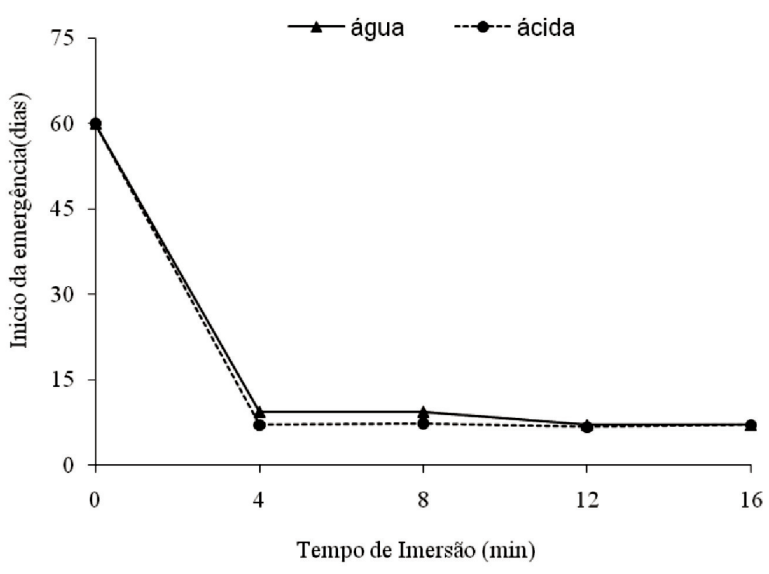

Figura 2-Início da emergência de mutamba (Guazuma ulmifolia Lam.) após a imersão em água ( $(\boldsymbol{\Lambda})$ e imersão em ácido sulfúrico $(\bullet)$ por diferentes períodos.

Figure 2 - Onset of the Emergency of Guazuma ulmifolia Lam. after immersion in water $(\mathbf{\Delta})$ and immersion in sulfuric acid $(\bullet)$ for different times.

Revista Árvore, Viçosa-MG, v.36, n.5, p.797-802, 2012
O índice de velocidade de emergência dos tratamentos realizados com ácido sulfúrico concentrado elevou-se à medida que aumentou o tempo de imersão da semente no ácido, atingindo o índice máximo de 1,6 em $8 \mathrm{~min}$. Concordando com esses resultados, Lopes et al. (2006) observaram aumento acentuado na velocidade de emergência de sementes de Ormosia nitida Vog quando escarificada com ácido sulfúrico por 10 min. Da mesma forma, Alves et al. (2006) também verificaram que o índice de velocidade de emergência foi máximo em sementes de Zizyphus joazeiro Mart. em um tempo de imersão de 100 min em ácido sulfúrico. Efeitos benéficos do ácido sulfúrico também foram verificados em sementes de Mimosa caesalpiniafolia Benth. (MARTINS et al., 1992), Copaifera langsdorffii Desf. (PEREZ; PRADO, 1993), Peltophorum dubium Taub. (PEREZ et al., 1999) e Bauhinia monandra Britt (ALVES et al., 2000).

O fato de o tegumento de uma semente se mostrar impermeável à água é fator importante para a formação de bancos de sementes no solo, pois estas germinaram de maneira desuniforme, fazendo que haja distribuição da germinação no tempo e no espaço. Tal fato possibilitará que a semente possua as condições necessárias para que as plântulas possam se estabelecer

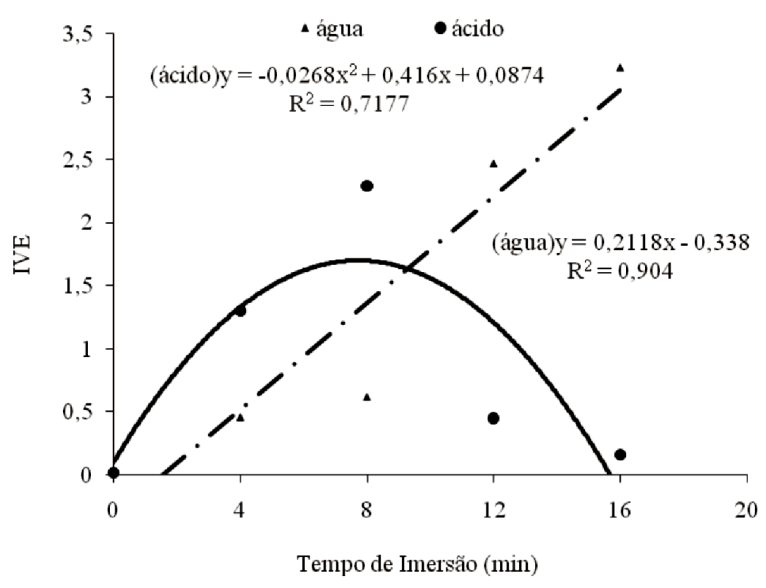

Figura 3 - Índice de velocidade de emergência de sementes de mutamba (Guazuma ulmifolia Lam.) após a imersão em água (ム) e imersão em ácido sulfúrico $(\bullet)$ por diferentes períodos.

Figure 3 - Vigor of Guazuma ulmifolia Lam. Seeds (index of emergence speed -IES), after immersion in

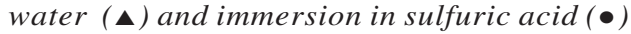
for different times. 
em condições naturais. Porém, é desvantajoso quando se desejam emergências rápidas e uniformes, nos processos que utilizam sementes em grandes quantidades (ROLSTON, 1978). No caso da mutamba, esse fato pode ser observado na Figura 2, em que o início da emergência das sementes não escarificada só ocorre cerca de 50 dias após o início da emergência das sementes que sofreram escarificação.

\section{CONCLUSÃO}

Os tratamentos pré-germinativos mostraram-se eficientes na superação da dormência de sementes de mutamba, sendo o método de imersão das sementes em água a $60^{\circ} \mathrm{C}$ por 16 min o mais indicado.

\section{REFERÊNCIAS}

ALVES, E. U. et al. Ácido sulfúrico na superação da dormência de unidade de dispersão de juazeiro (Zizyphus joazeiro Mart.). Revista Árvore, v. 30, n. 2, p.187-195, 2006

ALVES, M.C.S. et al. Superação da dormência em sementes de Bauhinia monandra Britt e Bauhinia ungulata L. - Caesalpinoideae.

Revista Brasileira de Sementes, v.22, n.2, p.139-144, 2000.

ARAÚJO NETO, J.C. Caracterização e germinação de sementes e desenvolvimento pós-seminal de mutamba (Guazuma ulmifolia Lam.). 1997. 81f. Dissertação (Mestrado em Ciências Agrárias) Universidade Estadual Paulista, Jaboticabal, 1997.

ARAÚJO NETO, J.C.; AGUIAR, I.B. Desarrollo ontogénico de plántulas de Guazuma ulmifolia (Sterculiaceae). Revista de Biologia Tropical, v.47, n.4, p.785-790, 1999.

ARAÚJO NETO, J.C.; AGUIAR, I.B. Germinative pretreatments to dormancy break in Guazuma ulmifolia Lam. seeds. Scientia Forestalis, n.58, p.15-24, 2000.

BARBOSA, J.M.; MACEDO, A.C. Essências florestais nativas de ocorrência no Estado de São Paulo: informações técnicas sobre sementes, grupo ecológico, fenologia e produção de mudas. São Paulo: Instituto de Botânica e Fundação Florestal, 1993. 125p.
BARBOSA, J. G. et al. Efeito da escarificação ácida e de diferentes temperaturas na qualidade fisiológica de sementes de Strelitzia reginae. Revista Brasileira de Sementes, v. 27, n.1, p.71-77, 2005.

BRASIL. Ministério da Agricultura e Reforma Agrária. Regras para análise de sementes. Brasília: SNDA/DNDV/CLAV, 1992.365p.

CARVAlho, N.M.; NAKAGAWA, J. Sementes: ciência, tecnologia e produção. 4. ed. Jaboticabal: FUNEP, 2000. 588p.

EIRA, M. T. S.; CALDAS, L. S. Seed dormancy and germination as concurrent processes. Revista Brasileira de Fisiologia Vegetal, v. 12, p. 85-104, 2000. (Edição especial).

EIRA, M. T. S.; FREITAS, R. W. A.; MELLO, C. M. C. Superação de dormência de sementes de Enterolobium contortisiliquum (Vell.) Morong.Leguminosae. Revista Brasileira de Sementes, v.15, n.2, p.177-181, 1993.

JÉLLER, H.; PEREZ, S.C.J.G.A.A. Dormência e temperatura em sementes de Cassia excelsa. Revista Brasileira de Sementes, v.21, n.1, p. 41-45, 1999.

HEYWOOD, V.H. Estratégias dos jardins botânicos para a conservação. Rio de Janeiro: Jardim Botânico do Rio de Janeiro, 1989. 69p. Tradução de Patrícia O. Mousinho, Luiz A.P. Gonzaga e Dorothi S.D. Araújo.

KRAMER, P.J.; KOZLOZWISKI, T.T. Fisiologia das árvores. Lisboa: Fundação Calouste Gulbenkian, 1972.745p.

LEMOS-FILHO, J.P. et al. Germinação de sementes de Senna macranthera, Senna multijuga e Stryphnodendron polyphyllum. Pesquisa Agropecuária Brasileira, v.32, n.4, p.357-361, 1997.

LOPES, J.C. et al. Tratamentos para acelerar a germinação e reduzir a deterioração das sementes de Ormosia nitida Vog. Revista Árvore, v.30, n.2, p.171-177, 2006.

Revista Árvore, Viçosa-MG, v.36, n.5, p.797-802, 2012 
LORENZI, H. Árvores Brasileiras: Manual de Identificação e Cultivo de Plantas Arbóreas Nativas do Brasil. Nova Odessa. Ed Plantarum, 2002. v.1.

MANGUIRE, J.D. Speed of germination aid in solection and evoluattion for seeding emergence and vigor. Crop Science, v.2, n.2, p.176-177, 1962.

MARTINS, C.C.; CARVALHO, N.M.; OLIVEIRA, A.P. Quebra de dormência de sementes de sabiá (Mimosa caesalpiniaefolia Benth.). Revista Brasileira de Sementes, v.14, n.1, p.5-8, 1992.

MAYER, A.M.; POLJAKOFF-MAYBER, A. The germination of seeds. 4.ed. New York: Pergamon Press, 1989. 270p.

NUNES, Y.R.F. et al. Germinação d Guazuma ulmifolia Lam. (Malvaceae) e Heteropterys byrsonimifolia A. Juss (Malpighiaceae) sob diferentes tratamentos d escarificação tegumentar. Unimontes Cientifica, v.8, n.1, p.43-52, 2006.

PEREZ, S.C.J.G.A.; FANTI, S.C.; CASALI, C.A. Dormancy break and light quality effects on seed germination of Peltophorum dubium Taub. Revista Árvore, v.23, n.2, p.131-137, 1999.

PEREZ, S.C.J.G.A.; PRADO, C.H.B.A. Efeitos de diferentes tratamentos pré-germinativos e da concentração de alumínio no processo germinativo de sementes de Copaifera langsdorfii Desf. Revista Brasileira de Sementes, v.15, n.1, p.115-118, 1993.

ROLSTON, M.P. Water impermeable seed dormancy. The botanical Review, v.44, n.33, p.365-396, 1978.

Revista Árvore, Viçosa-MG, v.36, n.5, p.797-802, 2012
SANTARÉM, E.R.; AQUILA, M.E.A. Influência de métodos de superação de dormência e do armazenamento na germinação de sementes de Senna macranthera (Colladon) Irwin \& Barneby (Leguminosae). Revista Brasileira de Sementes, v.17, n.2, p.205-209, 1995.

SCALON, S.P.Q. et al. Germinação e crescimento inicial de muda de orelha-demacaco (Enterelobium contortisiliqunn (Vell.) Morong): efeito de tratamentos químicos e luminosidade. Revista Árvore, v.30, n.4, p.529-536, 2006a.

SCALON, S. P. Q. et al. Armazenamento e tratamento pré-germinativos em sementes de jacarandá (Jacaranda cuspidifolia Mart.). Revista Árvore, v. 30, n. 2, p.179-185, 2006 b.

SMIDERLE, Os. J.; SOUSA, R. C. P. de. Dormência em sementes de paricarana (Bowdichia virgilioides Kunth - Fabaceae - Papilionidae). Revista Brasileira de Sementes, v.25, n.2, p.48-52, 2003.

SUÑÉ, A.D.; FRANKE, L.B. Superação de dormência e metodologias para testes de germinação em sementes de Trifolium riograndense Burkart e Desmanthus depressus Humb. Revista Brasileira de Sementes, v.28, n.3, p.29-36, 2006.

TELES, M. M. et al. Métodos para quebra da dormência em sementes de leucena (Leucaena leucocephala (Lam.) de Wit. Revista Brasileira de Zootecnia, v.29, n.2, p.387-391, 2000.

VAZQUEZ-YANES, C.; OROZCO-SEGOVIA, A. Patterns of seed longevity and germination in the tropical rainforest. Annual Review of ecology and Systematics, v.24, p.69-87, 1993 